\title{
Gas turbine modeling using adaptive fuzzy neural network approach based on measured data classification
}

\author{
Abdelhafid Benyounes ${ }^{1}$, Ahmed Hafaifa ${ }^{{ }^{*}}$, Abdellah Kouzou ${ }^{1}$ and Mouloud Guemana ${ }^{2}$
}

\author{
* Correspondence: hafaifa.ahmed. \\ dz@ieee.org \\ ${ }^{1}$ Applied Automation and Industrial \\ Diagnostics Laboratory, Djelfa \\ University, Tel:0213555233674, \\ Djelfa, Algeria \\ Full list of author information is \\ available at the end of the article
}

\begin{abstract}
The use of gas turbines is widespread in several industries such as; hydrocarbons, aerospace, power generation. However, despite to their many advantages, they are subject to multiple exploitation problem that need to be solved. Indeed, the purpose of the present paper is to develop mathematical models of this industrial system using an adaptive fuzzy neural network inference system. Where the knowledge variables in this complex system are determined from the real time input/output data measurements collected from the plant of the examined gas turbine. It is obvious that the advantage of the neuro-fuzzy modeling is to obtain robust model, which enable a decomposition of a complex system into a set of linear subsystems. On the other side, by focusing on the membership functions for residual generator to get consistent settings based on the used data structure classification and selection, where the main goal is to obtain a robust system information to ensure the supervision of the examined gas turbine.
\end{abstract}

Keywords: Gas turbine, Adaptive fuzzy neural network, Fuzzy inference modeling, Fuzzy clustering, Data measurements

\section{Background}

Gas turbines have become very effective in industrial applications for electric and thermal energy production in several industries. However, these rotating machines systems are complex and they are composed of several sensitive elements that are subject to some defects and operational risks [1-6, 7]. In the literature, several scientific studies have been done as tentative to the model development for the analysis of the dynamic behavior of these types of gas turbine machinery. On the other side, the physical model of a gas turbine can be obtained by dynamic simulations in the conception step, or based on real plant data of these types of machine in exploitation. Indeed, the models developed in the literature screens are complicated and are not exploitable in control strategy [8-13].

The developed model in this paper is reliable and easy to be implemented to ensure the control of the gas turbine system, which can provide a quick and an accurate estimation of the dynamic behavior of the studied gas turbine using the identification techniques based on the fuzzy neural networks. This model can be a suitable choice for the detection and the isolation of faults in gas turbine based on the generation of residues resulting from the comparison of the actual process

(C) 2016 The Author(s). Open Access This article is distributed under the terms of the Creative Commons Attribution 4.0 International License (http://creativecommons.org/licenses/by/4.0/), which permits unrestricted use, distribution, and reproduction in any medium, provided you give appropriate credit to the original author(s) and the source, provide a link to the Creative Commons license, and indicate if changes were made. 
variables measurements and the referential model output. It also helps to understand the dynamics of the gas turbine, suitable for the control system design based on predictive model of the gas turbine, which provides an acceptable quality prediction.

This paper presents a nonlinear model structure using the fuzzy clustering method and the adaptive fuzzy neural network inference system [14-17]. This structure was tested by the use of the real operational data obtained from a SOLAR TITAN 130 gas turbine which is being used for the gas injection application. An evaluation of this model is presented by comparing it with nonlinear autoregressive exogenous NARAX modeling method. Furthermore, several robustness tests were conducted in this work to validate the proposed fuzzy model. Indeed, the measured data observed in the input/output of the examined SOLAR TITAN 130 allowed to achieve the real-time modeling. On the other side, this phase has helped to identify the adequate model which can be exploited in the control of the studied gas turbine by the determination of some rules needed for the supervision of such system.

\section{Industrial application}

The gas turbine studied in this work (Solar Titan 130) is installed at the gas compression station SC3 SONATRACH Djelfa, Algeria. This gas turbine is composed of three most important sections: Axial compressor, combustion chamber and the turbine. It is obvious that the inlet guide vane (IGV) variable is located in the inlet of the axial compressor and the nozzle guide vane (NGV) is located in the turbine section [1].

Among the elements composing the gas turbine are the two flaps that are placed on the line of the fuel combustion chamber at the aspiration, both flaps are the main control tools of these machines. The first is used for controlling the fuel pressure at the aspiration side of the turbine and the second is used for controlling the speed of the load shaft, by the gas control valve (GCV) in the aspiration. The examined gas turbine in this work (TITAN 130 Solar) which is located at the Medjbara gas comression station SC3 SONATRACH at Djelfa, Algeria, is specifically designed for gas compression stations used in gas transportation. Figure 1 shows the diagram of the discussed gas turbine system and Table 1 presents it specifications.

\section{Gas turbine modeling}

In this paper, the fuzzy clustering is used for the initial study using a Takagi Sugeno inference system to determine the set of fuzzy rules. These rules given the fuzzy models of the dynamic behavior based on real data of the examined gas turbine. The fuzzy c-means clustering requires the existence of a multiple input and output data for the validations tests. This structure is used like an initial fuzzy inference system for the preparation of the adaptive fuzzy neural network inference system [18-20].

The variables of the studied gas turbine are the temperature and the mass fuel flow rate. The examined system has the sensors that provide the outputs measures, 


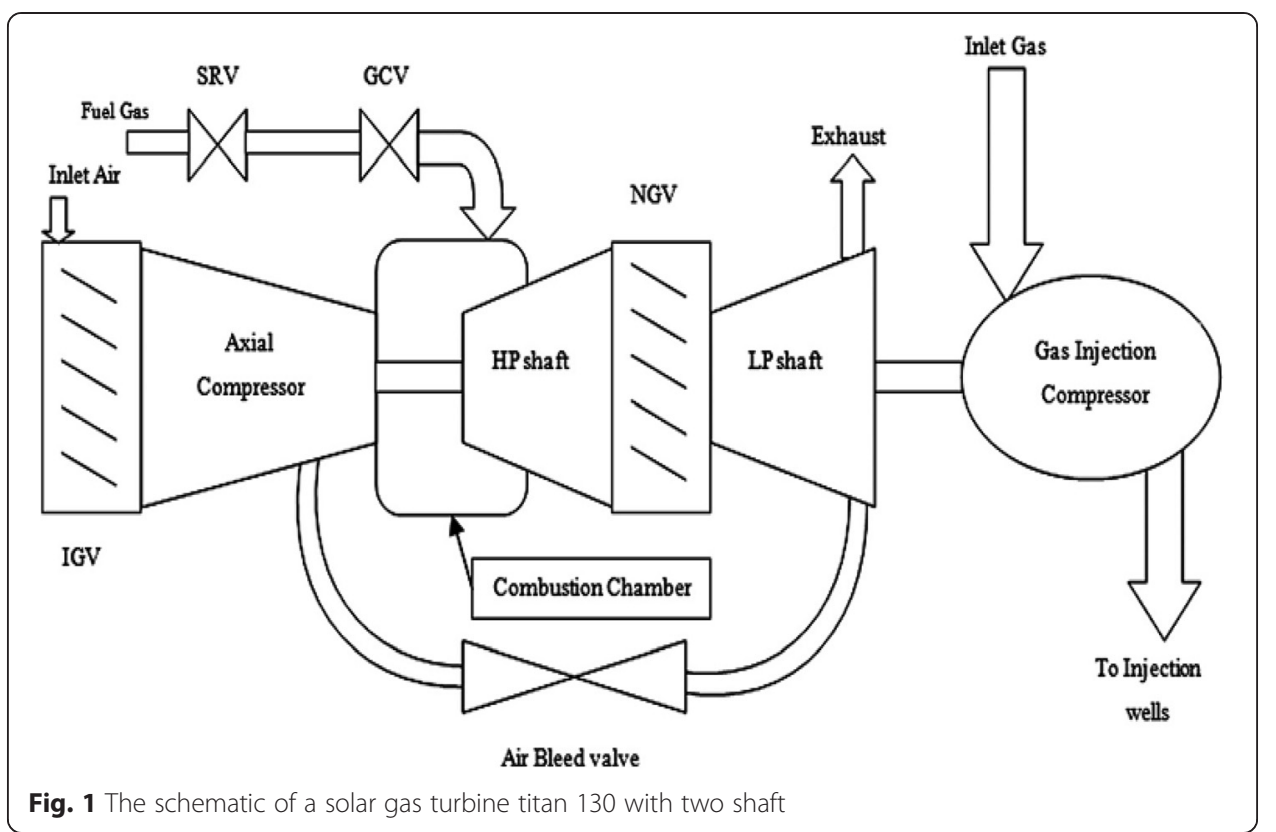

such as; the high pressure (HP), the shaft speed (NGP), the low pressure shaft speed (NPT) and the temperature of the blades. These measurements are used to provide different input-output data for the closed loop control, as it is represented in Fig. 2. Furthermore, there are other important variables such as; the air mass flow rate, the pressure ratio at the outlet of the axial compressor of the gas turbine and the fuel/air ratio.

\section{Algorithm of fuzzy clustering}

The fuzzy clustering algorithms were developed and tested in serval previous works [21-25], is a benchmark among different methods of fuzzy classification based on minimizing the objective function of the form:

$$
J_{F C M}(Z ; U ; V)=\sum_{i=1}^{c} \sum_{K=1}^{N}\left(\mu_{i k}\right)^{m} D_{i k A}^{2}
$$

Where $Z$ is the data set, $U=\left[\mu_{i k}\right]$ is the matrix of fuzzy partition $(c \times N), V=\left[v_{1}, v_{2}, \ldots v_{c}\right]$ is the vector of the center of classes to be determined, $v_{i} \in R^{n}$ is the center of the $i^{t h}$ class $1<i<c, m \in[1,+\infty]$ is a factor that denotes the degree of fuzziness of the partition.

Table 1 Examined gas turbine specifications

\begin{tabular}{ll}
\hline Quantity & Value \\
\hline Output Power & $15290 \mathrm{~kW}(20,500 \mathrm{hp})$ \\
Heat Rate & $9940 \mathrm{~kJ} / \mathrm{kW}-\mathrm{hr}(7025 \mathrm{Btu} / \mathrm{hp}-\mathrm{hr})$ \\
Exhaust Flow & $180050 \mathrm{~kg} / \mathrm{hr}(396,940 \mathrm{lb} / \mathrm{hr})$ \\
Exhaust Temperature & $505^{\circ} \mathrm{C}\left(940{ }^{\circ} \mathrm{F}\right)$ \\
Max Speed & $8855 \mathrm{rpm}$ \\
\hline
\end{tabular}




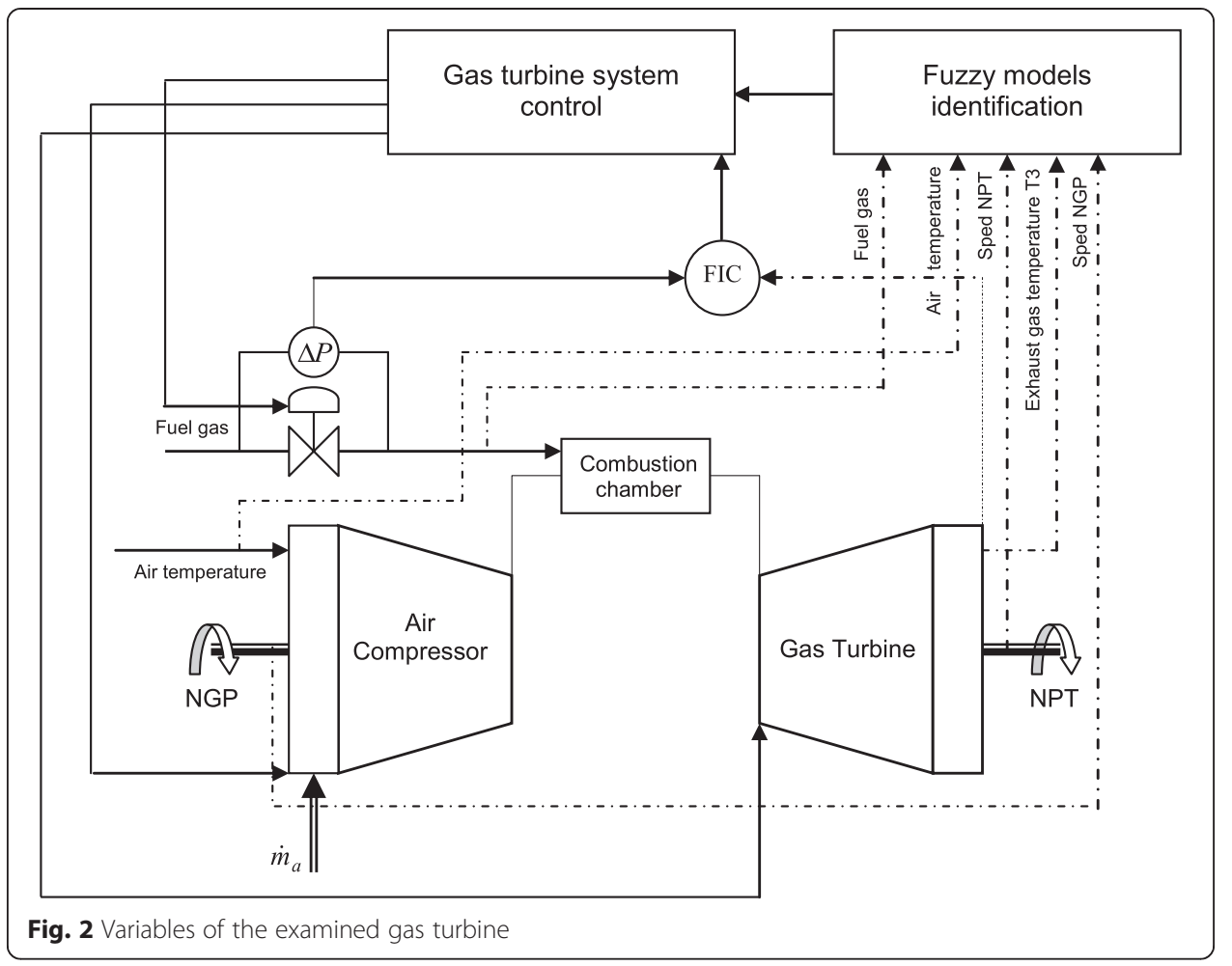

The standard quadratic distance in space in question, which defines the distance measure between the $z_{k}$ observation and the $v_{i}$ center within the meaning of the metric induced by $A$ is given by using the flowing equation:

$$
D_{i k A}^{2}=\left(z_{k}-v_{i}\right)^{T} A\left(z_{k}-v_{i}\right) \quad 1 \leq i \leq c, 1 \leq k \leq N
$$

In the Eq. (1), the measurement of non-similarity is expressed by the sum of squares of the distances between each data vector and the center of the corresponding class. The effect of this distance is weighted by the degree of activation $\mu_{i k}^{m}$ corresponding to the $z_{k}$ data vector, the value of the cost function $J_{F C M}(Z ; U ; V)$ can be seen as a measure of the total variance of $z_{k}$ with respect to the $v_{i}$ centers. The minimization of the objective function given in (1) is given as flows:

$$
\begin{aligned}
\mu_{i k} & =\frac{1}{\sum_{j}^{c} 1\left(\frac{D_{i k A}}{D_{j k A}}\right)^{\frac{2}{m-1}}} \quad 1 \leq i \leq c, 1 \leq k \leq N \\
v_{i} & =\frac{\sum_{K=1}^{N}\left(\mu_{i k}\right)^{m} z_{k}}{\sum_{K=1}^{N}\left(\mu_{i k}\right)^{m}}
\end{aligned}
$$

This leads to the Fuzzy C-Means clustering algorithm (FCM) given, which can be summarized in three steps:

Step 1: Calculation of the cluster centers 


$$
\mathrm{v}_{i}^{l}=\frac{\sum_{K=1}^{N}\left(\mu_{i k}^{(l-1)}\right)^{m} z_{k}}{\sum_{K=1}^{N}\left(\mu_{i k}^{(l-1)}\right)^{m}} 1 \leq i \leq c
$$

Step 2: Calculation of the distances

$$
D_{i k A}^{2}=\left(z_{k}-v_{i}^{l}\right)^{T} A\left(z_{k}-v_{i}^{l}\right) \quad 1 \leq i \leq c, 1 \leq k \leq N
$$

Step 3: Updating the partition matrix

If $D_{i k A}^{2}>0$ for $1 \leq i \leq c, 1 \leq k \leq N$

$$
\mu_{i k}^{(1)}=\frac{1}{\sum_{j}^{c} 1\left(\frac{D_{i k A}}{D_{j k A}}\right)^{\frac{2}{m-1}}}
$$

Where the function $1($.$) equal to 1$ for the positive values of the partition matrix and -1 for the negative values pf this matrix. When $m=1$ the partition matrix become zero (all terms are zero). Otherwise $\mu_{i k}^{(1)}=0$ if $D_{i k A}>0$ and $\mu_{i k}^{(1)} \in[0,1]$ with $\sum_{i}^{c} \mu_{i k}^{(1)}=1$ too $\left\|U^{(1)}-U^{(l-1)}\right\|<\varepsilon$.

\section{Adaptive fuzzy neural network system}

The optimization variables of the studied gas turbine are obtained by using fuzzy inference algorithms for the construction of the regions of data classified by the neural networks. These method increases the degree of calculating a fuzzy model using the neural networks layers structures. Therefore, this approach is typically referred to an adaptive fuzzy neural network inference system [14-16, 26-28]. Figure 3 gives an example of a fuzzy data clustering structure with $r$ rules signify as a neural network.

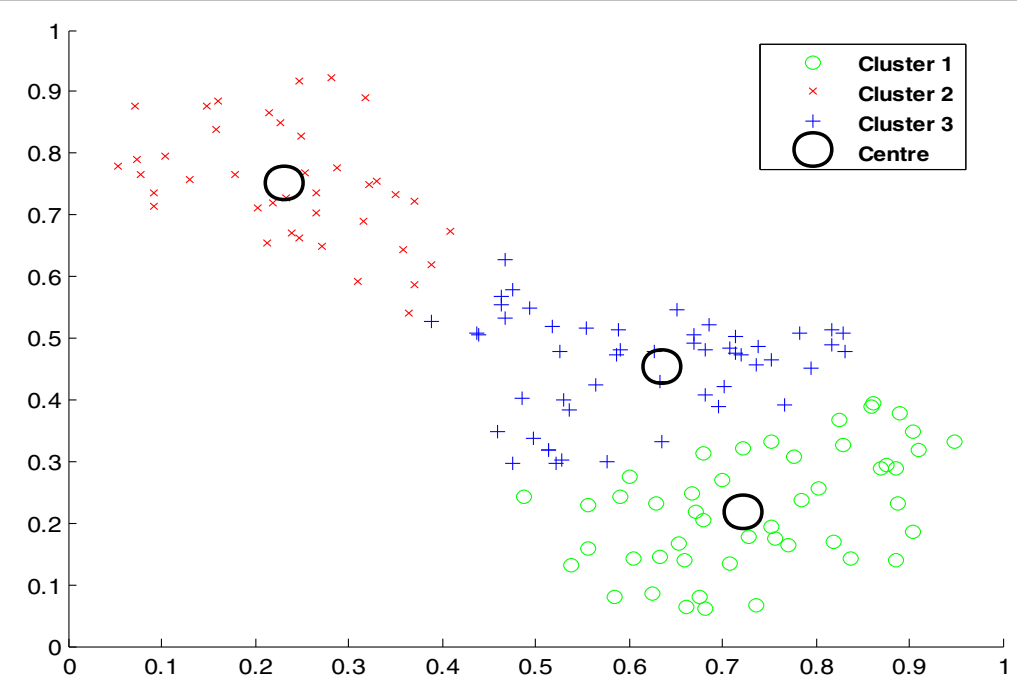

Fig. 3 Fuzzy data clustering structure 
The first layer nodes are calculated from the degrees of input in the fuzzy sets, and the nodes products in the second layer represent the operation of the antecedent conjunction. By normalization of the nodes $N$, the rules equations of the five layers are given in the following equations:

$$
\begin{gathered}
\text { Layer (1): } \quad \mu_{A_{i j}}\left(x_{j} ; c_{i j} ; \sigma_{i j}\right)=e^{-\left(\frac{x_{j}-c_{i j}}{2 \sigma_{i j}}\right)^{2}} \\
i=1, \ldots, N M F, j=1, \ldots, m \\
\text { Layer(2): } \quad w_{k}=\prod_{i=1}^{m} \mu_{A_{i k}}\left(x_{i}\right) k=1, \ldots, r \\
\text { Layer(3): } \quad \bar{w}_{k}=\frac{w_{k}}{\sum_{i=1}^{r} w_{i}} \\
\text { Layer(4): } \quad \bar{w}_{k} f_{k}=\bar{w}_{k}\left(p_{k 0}+\sum_{j=1}^{m} p_{k j} x_{j}\right) \\
\text { Layer(5): } \quad y=\sum_{i=1}^{r} \bar{w}_{i} f_{i}
\end{gathered}
$$

Where: $m$ is the number of inputs, $r$ is the number of rules, $N M F$ is the number of membership functions for each rule, $c_{i j}$ is the mean value, $\sigma_{i j}$ is the variance of each membership function, $f_{k}$ is the consequent part function and $P_{k j}$ represents the scalar coefficients.

In this work, the Takagi-Sugeno Fuzzy model is used to construct the ANFIS model for the examined gas turbine, this configuration is shown in Fig. 4, where three Gaussian membership functions for each input with an adjusting of the ANFIS variable by a combination using the least-squares method and the backpropagation gradient descent technique.

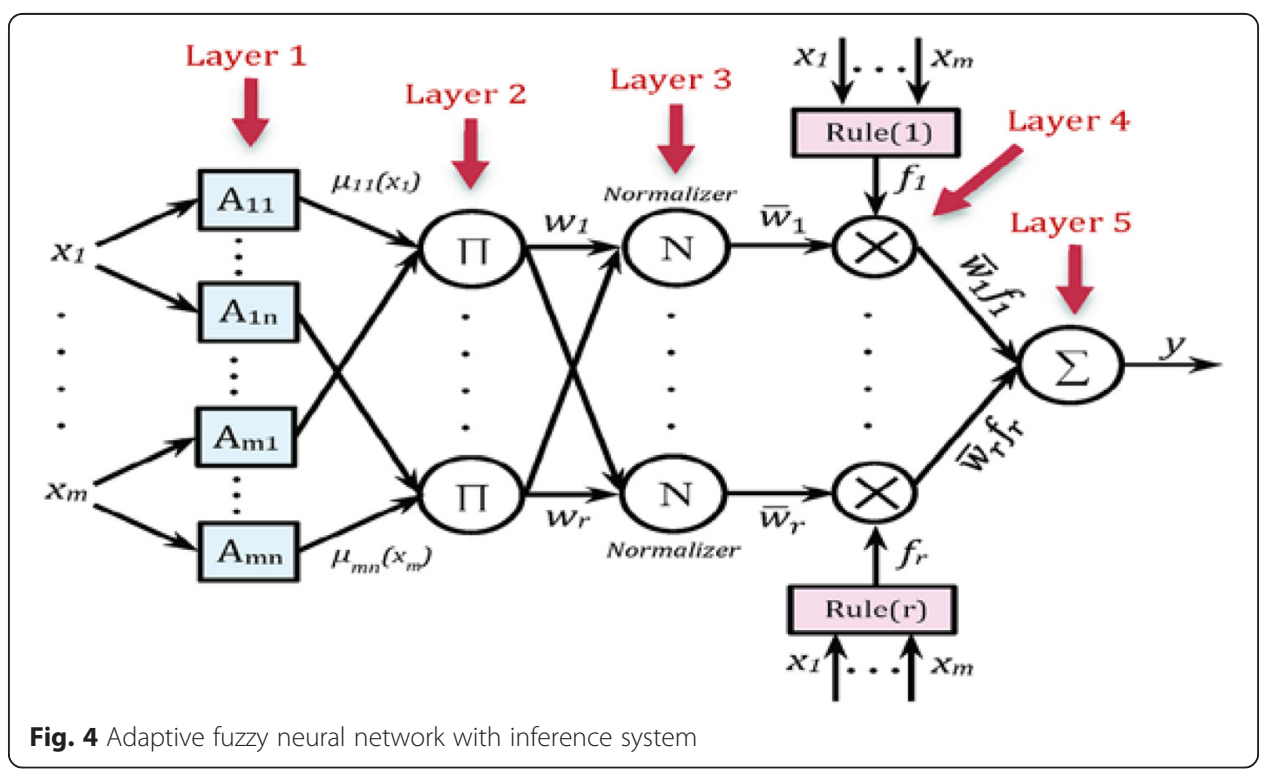


The nonlinear autoregressive exogenous model (NARX), which now is commonly used for the approximation of the dynamic behavior of complexes system, the MARX system output is given by $y(t)$ which represents the feedback to the input of the network and $u(t)$ is used for storing previous values of the sequences in the NARX model, is given by the Eq. 10:

$$
y(t)=F\left(\begin{array}{l}
y(t-1), y(t-2), \ldots ., y\left(t-n_{a}\right), \\
u(t-1), u(t-2), \ldots ., u\left(t-n_{b}\right)
\end{array}\right)
$$

Where: $y(t)$ is the output signal, $u(t)$ is the input signal, $n_{a}$ is the number of output regression, $n_{b}$ is the number of intput regression and $F$ is the nonlinear estimated function.

The estimated function $F$ may be have different mathematical arrangement. In this work a polynomial form is chosen, the nonlinear autoregressive exogenous model, is given by:

$$
\begin{aligned}
& y(t)=\alpha_{0}+\sum_{i_{1}=1}^{n} \alpha_{i_{1}} x_{i_{1}}(t)+\sum_{i_{1}=1}^{n} \sum_{i_{2}=i_{1}}^{n} \alpha_{i_{1}, i_{2}} x_{i_{1}}(t) x_{i_{2}}(t)+\ldots \\
& +\sum_{i_{1}=1}^{n} \ldots \sum_{i_{k}=i_{k-1}}^{n} \alpha_{i_{1}, \ldots . ., i_{k}} x_{i_{1}}(t) \ldots . x_{i_{K}}(t)
\end{aligned}
$$

Where: $n=n_{a}+n_{b}$ are scalar coefficients, $x_{i}(t)$ is the input data regression, $k$ is the nonlinearity degree in the estimated function $F$.

\section{Gas turbine investigation}

The model parameters of the examined gas turbine have been identified with a series of operational data at the startup, at the shutdown and at the normal operation phases. This identification is necessary for the overall gas turbine system decomposition into several subsystems, including the axial compressor, high pressure shaft (HP), low pressure shaft (LP) and the exhaust system, shown in Fig. 5.

\section{Axial compressor}

The two main variables are the discharge temperature $\left(\mathrm{T}_{\mathrm{C}}\right)$ and the pressure $\left(\mathrm{P}_{\mathrm{C}}\right)$ that can be modeled using the following expressions:

$$
\begin{aligned}
& T_{C}(k)=F_{1}\left(T_{C}(k-1), H P_{\text {speed } \%}(k-1), I G V(k-1), T_{A}(k-1)\right) . \\
& P_{C}(k)=F_{2}\left(P_{C}(k-1), H P_{\text {speed } \%}(k-1), I G V(k-1), N G V(k-1), T_{A}(k-1), P_{A}(k-1)\right)
\end{aligned}
$$



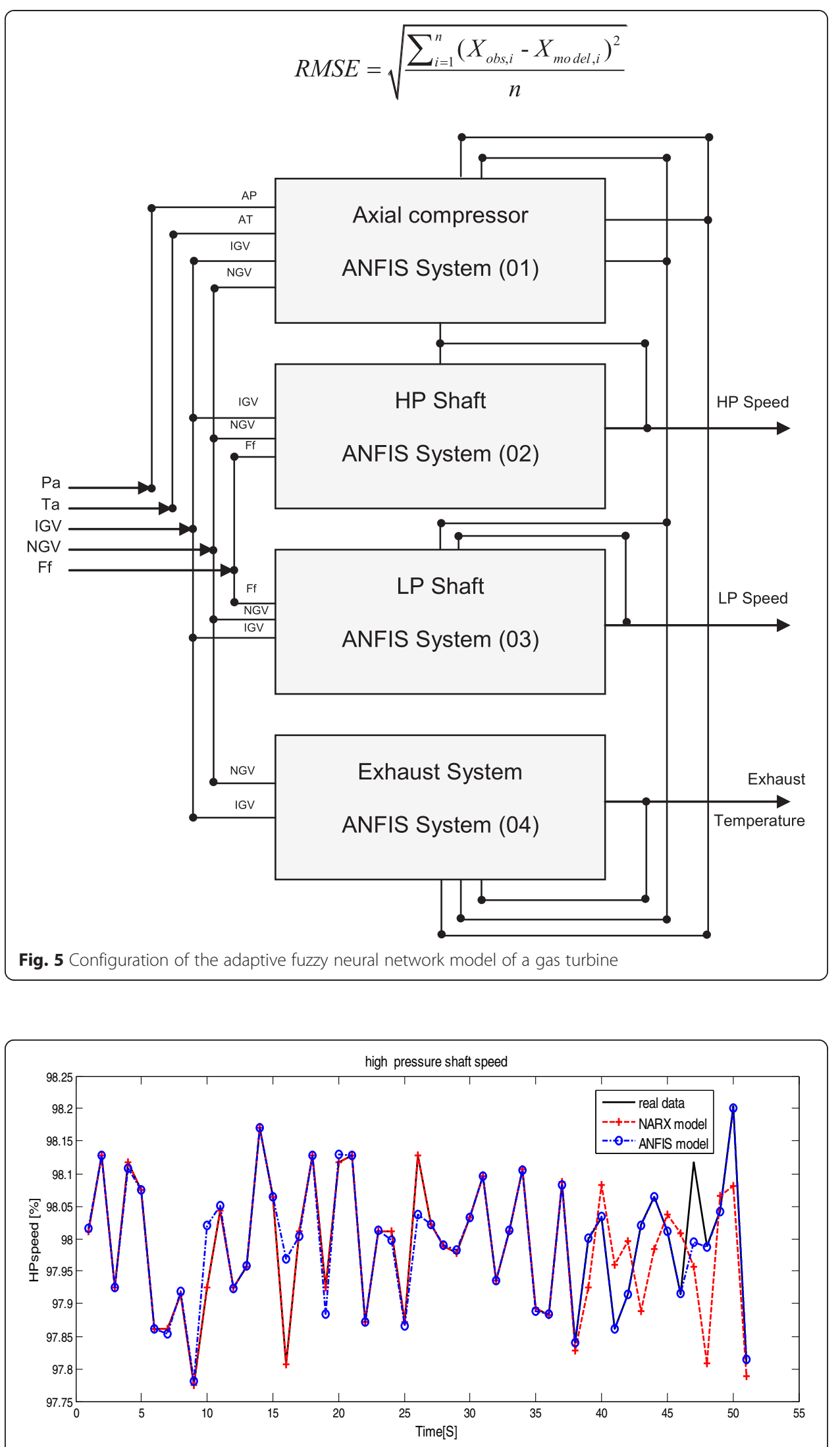

Fig. 6 High-pressure shaft speed ANFIS model validation 


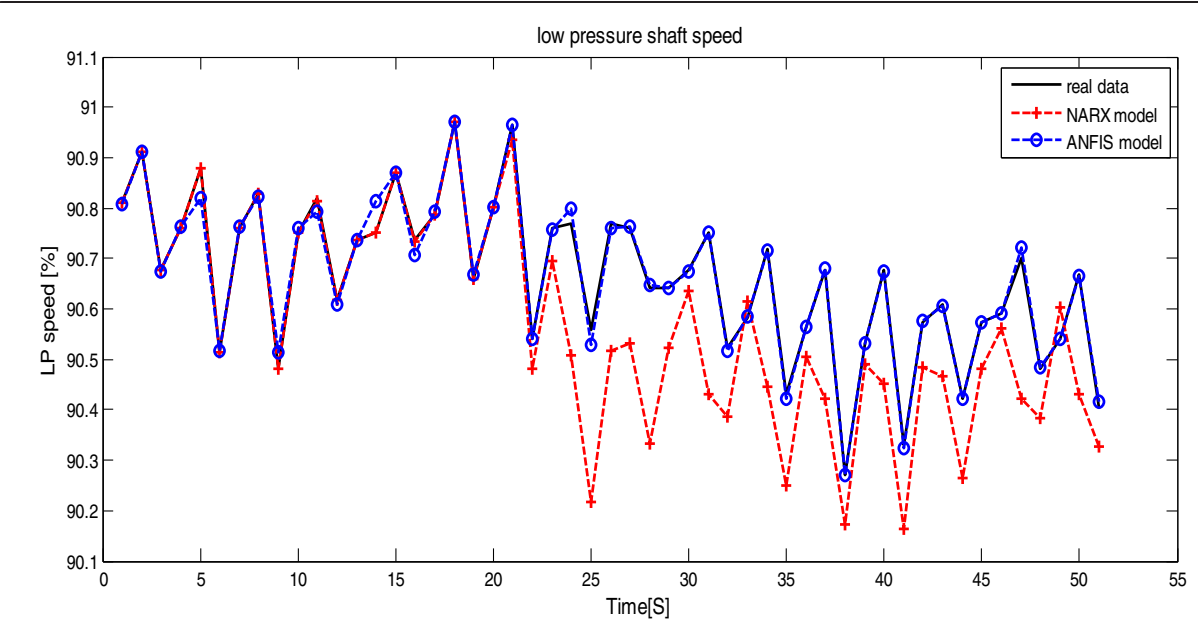

Fig. 7 Low-pressure shaft speed ANFIS model validation

$$
H P_{\text {speed } \%}(k)=F_{3}\left(H P_{\text {speed } \%}(k-1), F_{F}(k-1), N G V(k-1), I G V(k-1)\right) .
$$

\section{Low pressure shaft (LP)}

$$
\operatorname{LP}_{\text {speed } \%}(k)=F_{4}\left(L P_{\text {speed } \%}(k-1), P_{C}(k-1), F_{F}(k-1), N G V(k-1), I G V(k-1)\right)
$$

\section{Exhaust system (ET)}

$$
E T(k)=F_{5}\left(E T(k-1), A C D P(k-1), A C D T(k-1), I G V_{\text {final }}(k-1)\right)
$$

Where $F_{n}, n=1,2, \ldots, 5$ are fuzzy inference system variable that has been assembled from the real data of the examined turbine. TA and PA denote ambient temperature and pressure respectively, $\mathrm{FF}$ is fuel mass flow and $\mathrm{T}_{\mathrm{E}}$ is exhausted temperature. Figure 4 shows the overall configuration of the system modeling. The

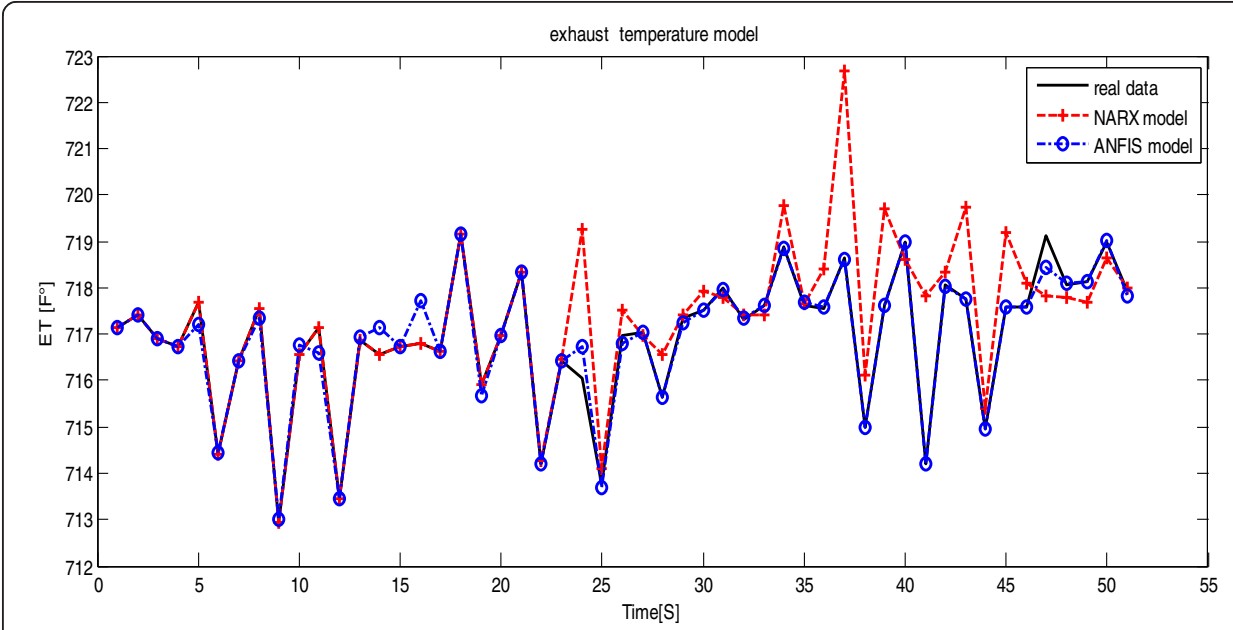

Fig. 8 High-pressure shaft speed ANFIS model validation 
Table 2 RMSE comparison between the two models

\begin{tabular}{llll}
\hline & \multicolumn{2}{l}{ Gas turbine parameter } \\
\cline { 2 - 4 } Model type & HP shaft speed & LP shaft speed & ET system \\
\hline ANFIS model $\times 10^{3}$ & 2,83 & 7,60 & 11,84 \\
NARX model $\times 10^{3}$ & 7,10 & 21,30 & 23,21 \\
\hline
\end{tabular}

parameter used for the comparison between the two models is the root mean square error (RMSE).

The root mean square error (RMSE) is the residues given by the difference between the actual and predicted values, obtiaied from a mean square error. Also this is an error measure used on values observed on the system state. The RMSE given in the Eq. 17 gives the estimation of the model predictions and is defined as the square root of the average squared error:

$$
R M S E=\sqrt{\frac{\sum_{i=1}^{n}\left(X_{o b s, i}-X_{\text {model }, i}\right)^{2}}{n}}
$$

The obtained results are shown in Figs. 6, 7 and 8, representing respectively the three main outputs of the model $\{$ HP, LP, ET\} for the ANFIS and naRAX models. The RMSE comparison between the two models is represented in Table 2.

The implementation equations of the laws, governing the gas turbine system leads to knowledge model too complex and delicate implementation. In the case
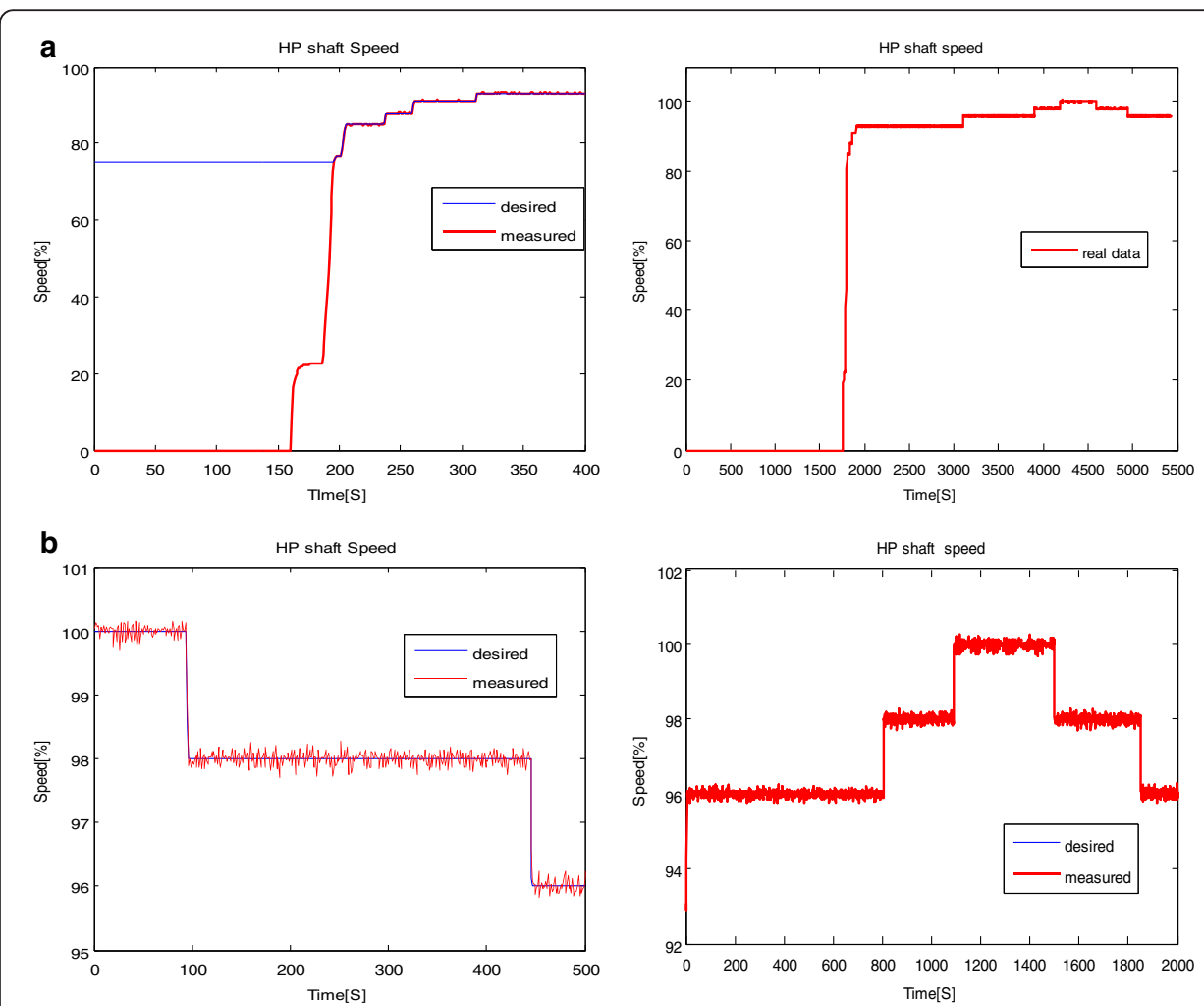

Fig. 9 a HP Shaft speed supervision with fuzzy controller using ANFIS model. b HP Shaft speed supervision with PID controller using ANFIS model 
considered, the modeling techniques developed from input/output measures collected from the system examined yield to good results for exploitable modeling in control of the examined gas turbine system.

When the knowledge of the expert is not available, the identification of a structure made from real data of the TITAN 130 Solar, installed in MEDJBARA gas comression station SC3 SONATRACH at DJELFA, Algeria, this method of fuzzy classification allows the partitioning of the data space into several classes for fuzzy models that are used for the control of the gas turbine variables. For the fuzzy self- tuning with PID controller using the ANFIS model for the examined solar turbine are given in the flowing Figs. 9a, b, 10a, b, 11a and b. The Fig. 9a show the responses of the HP shaft speed supervision with fuzzy controller using ANFIS model at the shutdown stage and the Fig. 9b show HP shaft speed supervision with PID controller using ANFIS model at the startup phase. The Fig. 10a show the responses of the LP shaft speed supervision with fuzzy controller and in the Fig. 10b the LP shaft speed supervision with PID controller is shown. The Fig. 11a shows the responses of the exhaust temperature supervision with fuzzy controller using ANFIS model and the Fig. 11b present the exhaust temperature supervision with PID controller.

The obtained results of the dynamic behavior control in the examined gas turbines are satisfactory, such behavior is a very important issue in oil and gas industry; because for these uncontrolled dynamic action can lead to premature aging of the components of the turbine, or unacceptable noise and vibration. This
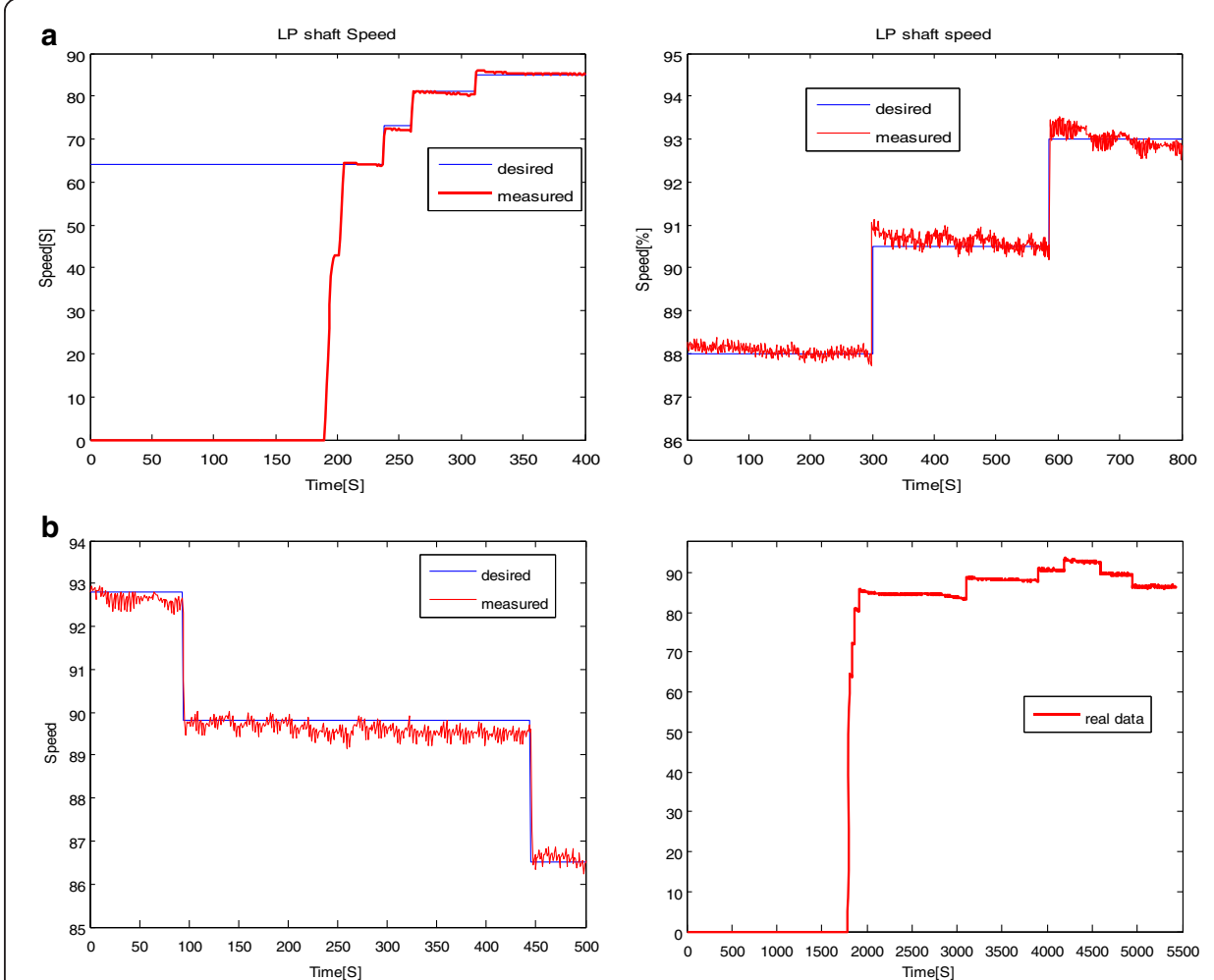

Fig. 10 a LP Shaft speed supervision with fuzzy controller using ANFIS model. b LP Shaft speed supervision with PID controller using ANFIS model 

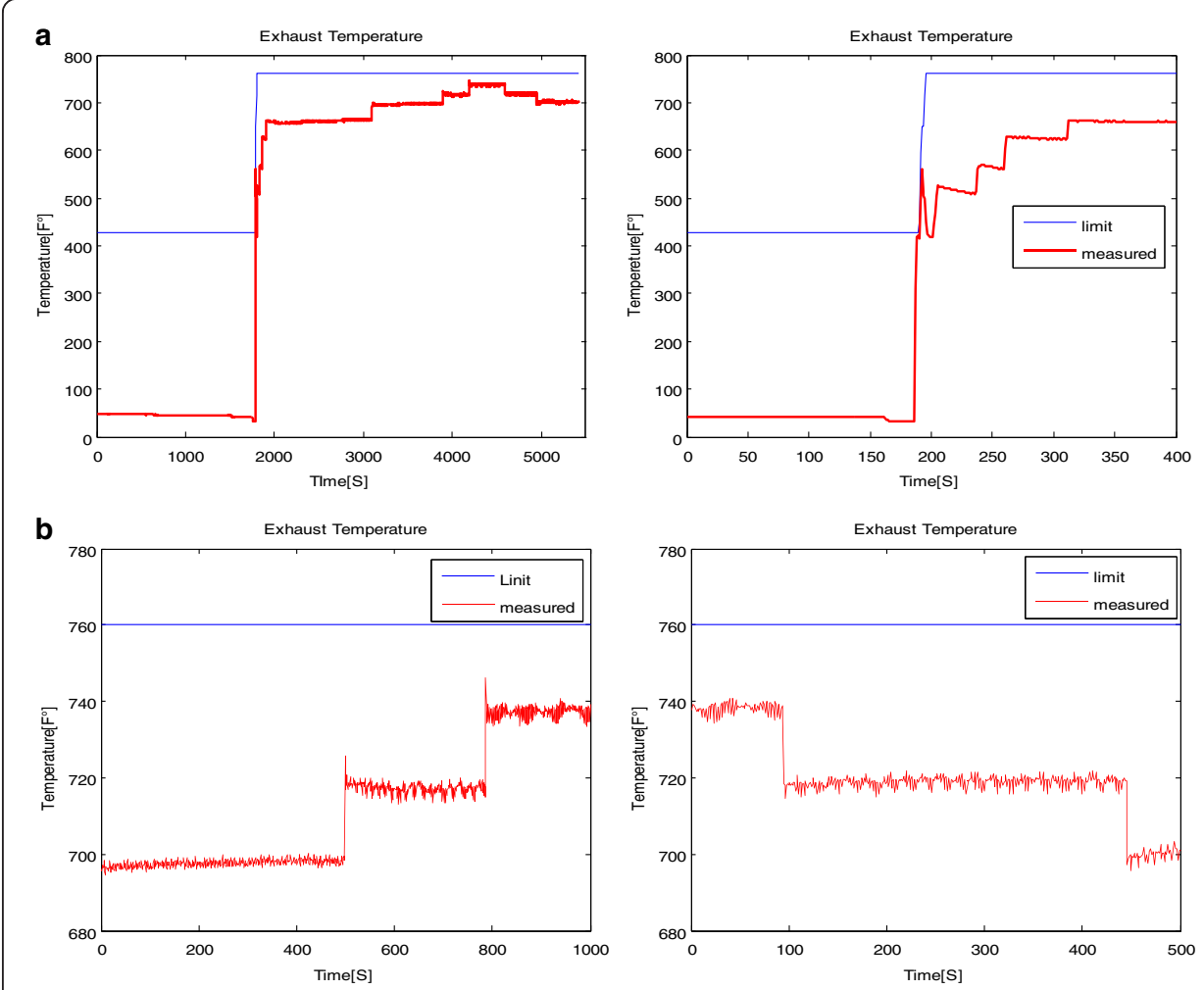

Fig. 11 a Exhaust temperature supervision with fuzzy controller using ANFIS model. b Exhaust temperature supervision with PID controller using ANFIS model

is particularly important to develop a robust control system, in the context of having a good operation of gas turbines.

The proposed approach in this work, allows an effective and a reliable control system for the examined gas turbine. Initially, the contribution of the fuzzy techniques for the modeling of different control parameters of the examined gas turbine is studied. This allows to develop a global model based on fuzzy clustering method using algorithms based on fuzzy inference systems for classification of real data of the examined gas turbine. Secondly, the ability of the application of fuzzy models to the controller synthesis based on fuzzy logic system is studied. The obtained results in this work are satisfactory and show the effectiveness of the proposed approach.

\section{Conclusion}

This work has presented one of the major problems when looking for a reliable mathematical representation of gas turbine variables; the proposed ANFIS model provides a good improvement in performance during its operation. The use of the fuzzy clustering algorithm has an important advantage which allows the automatic generation of the membership functions of the fuzzy regions from the studied data. The obtained results from data classification with the associated models construction offer advantageous performance in modeling of the examined gas turbine system. This approach can provide reliable models for controlling of such systems. 


\section{Competing interests}

This paper presents a nonlinear model structure using the fuzzy clustering method and the adaptive fuzzy neural network inference system using the measurements input /output data from the examined gas turbine plant. The evaluation of this model is presented by comparing it with nonlinear autoregressive exogenous NARAX modeling method. Furthermore, several robustness tests were conducted in this work to validate the proposed fuzzy model. Indeed, the measured data observed in the input / output of the examined SOLAR TITAN 130 allowed to achieve the real-time modeling. Where the main goal is to obtain a robust system information to ensure the supervision of the examined gas turbine. The List of abbreviations is not present, all variables and parameters are given in the text of the manuscript.

\section{Authors' contributions}

All authors read and approved the final manuscript.

\section{Author details}

${ }^{1}$ Applied Automation and Industrial Diagnostics Laboratory, Djelfa University, Tel:0213555233674, Djelfa, Algeria.

${ }^{2}$ Science and Technology Faculty, Médéa University, Djelfa, Algeria.

\section{Received: 14 February 2016 Accepted: 26 May 2016}

\section{Published online: 22 July 2016}

\section{References}

1. Benyounes A, Hafaifa A, Guemana M (2016) Gas turbine modelling based on fuzzy clustering algorithm using experimental data. J Appl Artif Intell 30(1):29-51

2. Benyounes A, Hafaifa A, Guemana M (2016) Fuzzy logic addresses turbine vibration on Algerian gas line. Oil Gas J. 22-28.

3. Hafaifa A, Mouloud G, Rachid B (2015) Fuzzy modeling and control of centrifugal compressor used in gas pipelines systems: Multiphysics Modelling and Simulation for Systems Design and Monitoring, book Series. Appl Cond Monit 2:379-389

4. Hafaifa A, Guemana M, Daoudi A (2015) Vibration supervision in gas turbine based on parity space approach to increasing efficiency. J Vib Control 21:1622-1632

5. Djeddi AZ, Hafaifa A, Salam A (2015) Operational reliability analysis applied to a gas turbine based on three parameter Weibull distribution. Mech 21(3):187-192.

6. Djeddi AZ, Hafaifa A, Salam A (2015) Gas turbine reliability model based on tangent hyperbolic reliability function. J Theor App Mech 53(3):723-730

7. Mohamed BR, Ahmed H, Mouloud G. Vibration modeling improves pipeline performance, costs. Oil Gas J. 2015:98-100.

8. Bezdek JC, Hathaway RJ (1987) Clustering with relational c-means partitions from pairwise distance data. Mathematical Modelling 9(6):435-439

9. Combescure D, Lazarus A (2008) Refined finite element modelling for the vibration analysis of large rotating machines: Application to the gas turbine modular helium reactor power conversion unit. J Sound Vib 318(4-5):1262-1280

10. Daniel G, Philippe Blanc, Evelyne A, Ivan V (2007) Active vibration control of flexible materials found within printing machines. J Sound Vib 300(3-5):831-846

11. Cheddie DF, Murray R (2010) Thermo-economic modeling of an indirectly coupled solid oxide fuel cell/gas turbine hybrid power plant. J Power Sources 195(24):8134-8140

12. Halimi D, Ahmed H, Bouali E (2014) Maintenance actions planning in industrial centrifugal compressor based on failure analysis. The quarterly Journal of Maintenance and Reliability 16(1):17-21

13. Ewins DJ (2010) Control of vibration and resonance in aero engines and rotating machinery - An overview. Int J Press Ves Pip 87(9):504-510

14. Yousef H (2015) Adaptive fuzzy logic load frequency control of multi-area power system. Int J Elect Power Energy Syst 68:384-395

15. Si J, Feng Q, Wen X, Xi H, Yu T, Li W, Zhao C (2015) Modeling soil water content in extreme arid area using an adaptive neuro-fuzzy inference system. J Hydrol 527:679-687

16. Taherdangkoo M, Bagheri MH (2013) A powerful hybrid clustering method based on modified stem cells and Fuzzy C-means algorithms. Eng Appl Artif Intel 26(5-6):1493-1502

17. Ng WB, Syed KJ, Zhang Y (2005) The study of flame dynamics and structures in an industrial-scale gas turbine combustor using digital data processing and computer vision techniques. Exp Therm Fluid Sci 29(6):715-723

18. Rahme S, Meskin N (2015) Adaptive sliding mode observer for sensor fault diagnosis of an industrial gas turbine. Control Eng Pract 38:57-74

19. Setnes M, Babuška R, Verbruggen HB (1998) Complexity reduction in fuzzy modeling. Math Comput Simul 46(5-6):507-516

20. Ganjefar S, Tofighi M, Karami H (2015) Fuzzy wavelet plus a quantum neural network as a design base for power system stability enhancement. Neural Netw 71:172-181

21. Arsalis A (2008) Thermoeconomic modeling and parametric study of hybrid SOFC-gas turbine-steam turbine power plants ranging from 1.5 to 10 MWe. J Power Sources 181(2):313-326

22. Babuška R, Verbruggen HB (1995) Identification of composite linear models via fuzzy clustering. Proceedings of the European Control Conference, Rome, Italy, pp 1207-1212

23. Roubos JA, Mollov S, Babuška R, Verbruggen HB (1999) Fuzzy model-based predictive control using Takagi-Sugeno models. Int J Approx Reasoning 22(1-2):3-30

24. Takagi T, Sugeno M (1985) Fuzzy identification of systems and its applications to modelling and control. IEEE Trans Syst Man Cybern SMC-15(1):116-132 
25. Lendek Z, Lauber J, Guerra TM, Babuška R, De Schutter B (2010) Adaptive observers for TS fuzzy systems with unknown polynomial inputs. Fuzzy Set Syst 161(15):2043-2065

26. Noiray N, Schuermans B (2013) Deterministic quantities characterizing noise driven Hopf bifurcations in gas turbine combustors. Int J Non-Linear Mech 50:152-163

27. Ata R (2015) Artificial neural networks applications in wind energy systems: a review. Renew Sustain Energy Rev 49:534-562

28. Tzou H-S (1991) Distributed vibration control and identification of coupled elastic/piezoelectric shells: Theory and experiment. Mech Syst Signal Process 5(3):199-214

Submit your manuscript to a SpringerOpen ${ }^{\circ}$ journal and benefit from:

- Convenient online submission

- Rigorous peer review

- Immediate publication on acceptance

- Open access: articles freely available online

- High visibility within the field

- Retaining the copyright to your article

Submit your next manuscript at $\boldsymbol{s p r i n g e r o p e n . c o m ~}$ 